\title{
The scientific basis of health services
}

\author{
Needs a better balance between original and evaluative research
}

The relation between science and health services has until recently been too casual, said Alan Langlands, chief executive of the National Health Service (NHS), at last week's London conference on the scientific basis of health services. The primary job of medical research has been to understand the mechanisms of disease and produce new treatments, not to worry about the effectiveness of the new treatments or their implementation. As a result many new treatments have taken years to become part of routine practice, ineffective treatments have been widely used, and medicine has been opinion rather than evidence based. "There has been," said Sam Their, president of the Massachusetts General Hospital, "a failure of leadership in health research and too little investment in assessing new technologies."

Yet in the United States the new congress is proposing to increase the $\$ 11.25$ billion budget of the National Institutes of Health (primarily original research) by $5 \cdot 7 \%$ and slash the $\$ 159$ million budget of the Agency for Health Care Policy and Research (primarily evaluative research) to $\$ 64$ million. This is a mistake: one of Britain's most prominent biological researchers Mark Ferguson, dean of the school of biological sciences in Manchester, said at last week's conference: "Development has been limited by the rate of discovery, but now it's limited by the rate of implementation." "What we need," said Sir Michael Peckham, director of the NHS research and development programme and organiser of the conference, "is a map of best practice rather like the human genome map. We need to bring together the methods of science to benefit the products of science."

Britain cannot claim to lead the world in many aspects of medicine, but it does seem to be ahead of almost all other countries (except perhaps the Netherlands) in recognising that science needs to be an integral part of health services. That recognition began in 1988 when the House of Lords select committee on science and technology observed that the NHS had almost no research capability of its own. ${ }^{1}$ Instead, most research was undertaken by the Medical Research Council (funded by the Department of Education and Science rather than the Department of Health), the medical charities, or the pharmaceutical industry. Yet the NHS is an organisation whose performance depends critically on the quality of its knowledge. The House of Lords recommended that the NHS needed its own research capability, and the result was the NHS research and development programme with its director sitting on the NHS executive. In other words, research and development was placed at the heart of the NHS. And at last week's conference both Alan Langlands and Stephen Dorrell, the Secretary of State for Health, spoke strongly in favour of an evidence based health service. "Research and development," said Mr Dorrell, "is not an optional extra. It must be a core function of the NHS. That is why each health authority in Britain is required to make a contribution towards the NHS research and development budget (p 970)."

Michael Peckham began as the first NHS director of research and development in 1990, and he will be replaced at the end of this year by John Swales, professor of medicine in Leicester. The programme has developed ways of determining the questions that matter to the health service and patients, prioritising those questions, designing programmes to answer them, disseminating the results, and trying to ensure that they are actually introduced into practice. In the beginning many members of the research community were suspicious of the NHS programme: they thought that there was lots of rhetoric, process, and fancy diagrams but no results. Suspicions remain, but the evidence presented in the 1995 report on medical research by the House of Lords showed that most researchers are now convinced of the logic and benefits of the programme. ${ }^{2}$ It is also a tribute to Sir Michael that over a 1000 people from 40 countries turned up to this first conference on the scientific basis of health services.

But-warned both Professor Their and Tony Culyer, professor of economics in York and author of a government review of research in the $\mathrm{NHS}^{3}$ - there is a need to win the hearts and minds of the public, managers, health providers, and policy makers to get them to commit themselves to research. The benefits of research are obvious to researchers, but they are not so obvious to these important constituencies - which is why the American congress had no qualms about cutting the budget of the Agency for Health Care Policy and Research. Britain may seem to be in a good position with its commitment from the top to spend $1.5 \%$ of the NHS budget of $£ 41$ billion on research and development, but Professor Culyer is worried both that hard pressed health authorities may be tempted to divert resources into services and that researchers may not rise to the challenge of providing health authorities with the research services they need. In many other countries those at the top still have to be convinced of the value of evaluative research, and the conference heard how few of those responsible for health services in the developing world see the value of the research. Yet perhaps 
when resources are tight health authorities should spend a higher proportion of their revenue on research and evaluation.

Another potential danger is researchers fighting with each other. Too often those who believe in randomised controlled trials are scornful of those interested in observational research, while biostatisticians mock economists, quantitative researchers question the value of qualitative research, and basic scientists denigrate clinical research. Professor Their called on researchers to avoid fighting each other, saying: "Nobody here has a methodology that will answer all my needs." Those who care about health must make sure that they are using the best methods to answer the tough questions they confront. And the discussions at the conference provided many examples of where researchers could get real assistance from other disciplines.

The conference heard many times about the enormous scientific excitement that is being generated by the new biology and how molecular biology is drawing together clinical researchers who previously worked on disparate physiological systems. Tom Lee, who runs the clinical effectiveness training programme at Harvard, described how studying methods for evaluating clinical practice was doing exactly the same: those evaluating treatments in gynaecology can work together with, and learn from, those evaluating gastroenterological treatments.

The central message of this conference was that health services need both research that will develop new ideas and treatments and research that will help evaluate them and ensure that those that are effective are introduced rapidly into treatment.

RICHARD SMITH Editor

$B M f$

London WC1H 9JR

\footnotetext{
1 House of Lords Select Committee on Science and Technology. Priorities in medical research. London: HMSO, 1988.

2 House of Lords Select Committee on Science and Technology. Medical research and the NHS reforms. London: HMSO, 1995.

3 Research and Development Task Force. Supporting Research and Development in the NHS. London HMSO, 1994.
}

\section{Consensus on red cell transfusion}

\section{Critically ill patients are often short of blood}

Perioperative blood and red cell transfusion in elective surgery varies, apparently without justification, among clinical units. ${ }^{1}$ Guidelines have not been agreed about when to give a transfusion and how much blood to give. Evidence has not been gathered to justify the heterogeneity of transfusion practice, which exposes recipients to numerous hazards, albeit a small risk per "donor exposure."2

Previous attempts have been made to establish guidelines: in 1988 the US National Institutes of Health's consensus conference on perioperative transfusion proposed that a haemoglobin concentration of $<70 \mathrm{~g} / 1$ justified transfusion. The recommendations, however, were so hedged around with the need to consider patients' clinical problems individually that the suggested haemoglobin concentration was only a small component in the decision. ${ }^{3}$ This is entirely appropriate as the haemoglobin concentration or packed cell volume alone gives insufficient information on which to base a decision to give a transfusion.

These uncertainties explain the consensus conference at the Royal College of Physicians of Edinburgh last year. Topics that were discussed included variations in transfusion practice and their clinical outcome, clinical guidelines and protocols, blood components and synthetic alternatives that carry oxygen, autologous transfusion, the need to give relevant information to patients about hazards and benefits, and, finally, means of achieving changes in clinical transfusion practice. ${ }^{4}$ The consensus statement that emerged carries clear therapeutic guidelines only a little further, and it calls for more research to help the decision on red cell or blood transfusion.

For the past 30 years transfusion specialists have sought to minimise blood transfusion, thereby avoiding avoidable hazards and using it only in patients who genuinely need it. Risks include the transmission of (especially viral) infection; immune modulation, leading to an increase in postoperative wound infections and perhaps later development of metastatic malignancy; and disasters due to clerical error, ${ }^{5}$ which autologous transfusion does not avoid. Increased awareness of these risks has led to better medical education; the adoption of maximum surgical blood ordering schedules, which establish the appropriate number of packs of blood that should be available as a precaution to replace blood loss during elective surgical procedures; and closer attention to operative haemostasis.

\section{Risk of undertransfusion}

Guidelines have been published by the British Committee for Standards in Haematology, usually in haematological journals. $^{2}$ Topics include the use of fresh frozen plasma, platelets, and transfusion schedules for infants and children. ${ }^{6}$ The need for further guidelines, however, is well recognised. These will have to be based on research, which should lead to the development of physiologically and clinically rational bases for red cell and blood transfusion-for example, after trauma and surgical blood loss. Consensus is needed not only on "triggers" prompting transfusion but also on "targets"that is, clinical and laboratory indicators that the volume of blood transfused is adequate to meet the individual patient's need for circulatory support, thereby avoiding further transfusions, with their inherent risks.

Despite the desirability of adopting ways to minimise transfusion we must not forget the risks of undertransfusion in some groups of patients who are critically ill. ${ }^{7}$ Preterm infants denied placental transfusion at birth, ${ }^{8}$ patients after cardiovascular surgery and neurosurgery, ${ }^{9-11}$ and patients dependent on a ventilator in intensive care or high dependency units fall into this category. Undertransfusion increases patients' risks of prolonged dependence on respiratory support with all its costs and complications, including infections and inadequate organ perfusion, leading to cardiac ischaemia, ${ }^{10}$ lung dysfunction, renal impairment, and multiple organ failure. ${ }^{12}$

As a guide to the adequacy of the individual patient's blood for oxygen transport and organ perfusion, which determines the outcome in critical illness, the haemoglobin concentration 